\title{
Modification of trabeculectomy to avoid postoperative hyphaema. The 'guarded anterior fistula' operation
}

\author{
A G P Konstas, J L Jay
}

\begin{abstract}
The effect of varying the position of a trabeculectomy fistula on the rate of postoperative hyphaema was studied in a prospective randomised trial. One eye of each of 78 consecutive patients with primary open angle glaucoma and exfoliation glaucoma was allocated to one of two groups. In group A the fistula was fashioned anterior to the scleral spur, entirely in corneal tissue. In group B the fistula included cornea and sclera with trabecular meshwork and scleral spur. Seven out of 39 eyes (18\%) in group A developed a postoperative hyphaema with detectable blood level, compared with 22 out of 39 eyes (56\%) for group $B(p<0.001)$. In addition, the severity of the bleeding was greater in group $B$, and the three cases of recurrent bleeding were all in this group. Group B patients remained in hospital for an average of 3.9 days, which was significantly longer $(p=0.004)$ than the average of 2.9 days for group $A$. This difference was related to the frequency and severity of the hyphaema. The type of dissection or the occurrence of hyphaema did not influence the intraocular pressure at $\mathbf{4}$ months after surgery.
\end{abstract}

Tennent Institute of Ophthalmology, Western Infirmary, 38 Church Street, Glasgow G11 6NT

A G P Konstas

J L Jay

Correspondence to: Dr A G P Konstas. Accepted for publication 21 November 1991
Trabeculectomy is the standard drainage operation for primary open angle glaucoma. ${ }^{1-4}$ Its main advantage over full thickness drainage procedures is a reduced incidence of complications. $^{5-8}$ The success and safety of the procedure have been established, ${ }^{-12}$ so that recently there has been a tendency towards earlier surgery. ${ }^{13-15}$
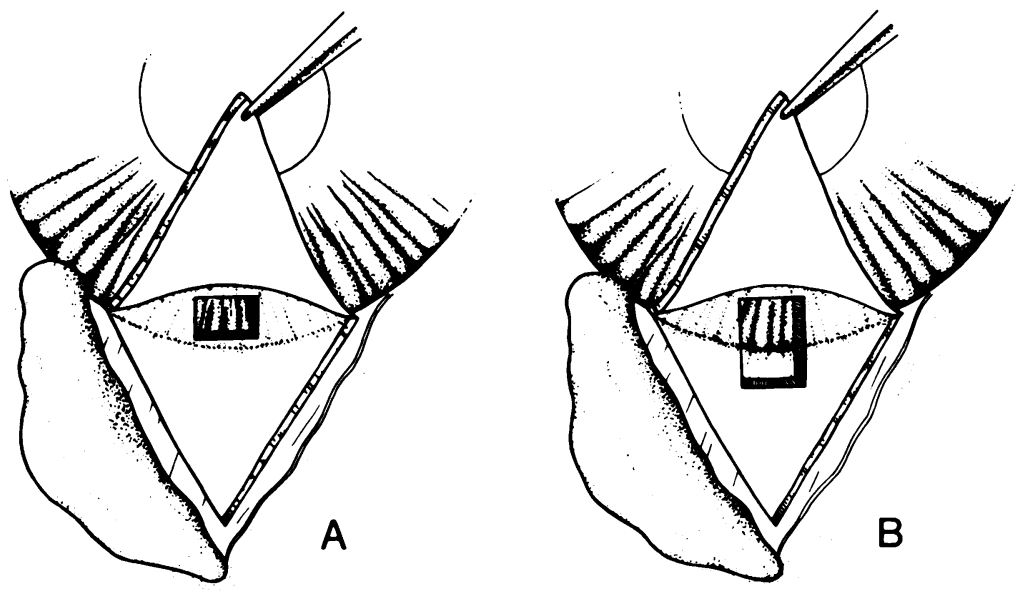

Figure 1 Schematic drawing of the area of tissue excised to fashion the fistula. In group A the dissection was anterior to the scleral spur and included only corneal tissue. Group $B$ had excision of corneal and scleral tissue incorporating scleral spur and trabecular meshwork.
Nevertheless, operation may be delayed because of fears that there may be surgical complications. The frequency of postoperative hyphaema varies from 15 to $53 \%,{ }^{16-22}$ and though it is seldom a serious complication it may prolong the patient's stay in hospital. It may also cause temporary reduction in vision, which may be a serious handicap if vision is poor in the other eye. We therefore designed this study to confirm and quantify our observation that excising the inner block anterior to the scleral spur reduced the frequency of postoperative hyphaema.

\section{Patients and methods}

A randomised prospective trial was set up to study first trabeculectomies for primary open angle glaucoma and exfoliation glaucoma (alternatively referred to as pseudoexfoliation glaucoma). One eye of 78 consecutive patients operated on between October 1989 and November 1990 was randomly allocated to either group A or group B by means of a table of random numbers. The allocation was identified from the code by the senior operating theatre nurse at the start of the operation, and 13 surgeons took part. Group A had the inner block fashioned and excised entirely anterior to the scleral spur so that only corneal tissue was excised (Fig 1). Group B had a conventional inner block of corneoscleral tissue extending posterior to the scleral spur with the trabecular meshwork near the centre of the excised tissue. ${ }^{2+}$ Nine other patients with primary open angle glaucoma who underwent a trabeculectomy during the course of the trial were excluded. The reasons were failure to allocate a randomisation (two), reluctance of the surgeon to take part (four), other reseach requirements (three).

All degrees of severity of glaucoma were included in the trial, irrespective of level of intraocular pressure, visual field loss, optic disc cupping, or duration of medical treatment. Patients with closed angle glaucoma, secondary glaucomas, previous ocular surgery, and concurrent ocular inflammation were excluded. Eighteen patients undergoing combined extracapsular cataract extraction and trabeculectomy were also excluded from this study. All patients were examined preoperatively according to a predetermined protocol. The following information was recorded: sex, age, diabetes mellitus, arterial hypertension, haematological disorders, reason for diagnosis, and details of glaucoma at time of diagnosis (intraocular pressure without treatment, cup to disc ratio, and visual field). The same glaucoma details at the time of operation (including the intraocular 
pressure on medical therapy) were recorded together with the time from diagnosis to operation. The indication for surgery (uncontrolled intraocular pressure, progression of visual field loss, both, intolerance to medications, and poor compliance) was also noted. The visual field loss was graded according to the classification by Jay and Murray. ${ }^{1+}$ All patients were examined by slit-lamp biomicroscopy and gonioscopy prior to surgery for the presence of exfoliation.

The operations were performed under local or general anaesthesia. Following the insertion of a superior rectus suture, a flap of conjunctiva and Tenon's capsule was reflected as shown in Figure 1. A rectangular or triangular half-thickness outer scleral flap was fashioned measuring approximately $4 \times 4 \mathrm{~mm}$. The edges of this flap were not extended into the cornea beyond the limbus. The inner block was dissected as described above according to the random allocation. A peripheral iridectomy was performed in all cases, and the superficial flap was sutured with one to three sutures. The conjunctiva was closed with continuous or interrupted sutures. Viscoelastic substances were not used.

To ascertain the accuracy of dissection with respect to the scleral spur the surgical specimen was fixed immediately after excision in buffered glutaraldehyde $2 \cdot 5 \%$. The dimensions of the excised tissue were recorded, and all specimens were examined with a dissecting microscope at a $\times 50$ magnification. Where doubt still existed as to the location of the dissected block, paraffin histology was used for confirmation. Similar histological confirmation was carried out in a random $25 \%$ sample of all specimens. If any part of the scleral spur or trabecular meshwork was found in the specimens from group $A$, the case was reclassified as group B (posterior dissection). Similarly, inability to demonstrate anatomical structures consistent with the excision of a posterior block (scleral spur, part of the outflow system) in a specimen from group B led to its transfer to group A. The name of the surgeon was recorded together with his comments as to whether there had been bleeding into the anterior chamber.

Postoperatively patients were examined every day while in hospital, and the following infor-

Table 1 Details of patients. There was no statistical difference between the study groups for the features indicated

\begin{tabular}{lllllll}
\hline & $n$ & Mean age & $\begin{array}{l}\text { Male/female } \\
\text { ratio }\end{array}$ & $\begin{array}{l}\text { Arterial } \\
\text { hypertension }\end{array}$ & $\begin{array}{l}\text { Diabetes } \\
\text { mellitus }\end{array}$ & Thrombocytopenia \\
\hline Group A & 39 & $68 \cdot 6(10 \cdot 4)$ & $20 / 19$ & 12 & 1 & 0 \\
Group B & 39 & $67 \cdot 7(9 \cdot 1)$ & $21 / 18$ & 7 & 1 & 1 \\
\hline
\end{tabular}

Standard deviations in parentheses.

Table 2 Details of glaucoma features at diagnosis and at the time of operation, with duration of preoperative medical therapy. The groups were not statistically different

\begin{tabular}{|c|c|c|c|c|c|c|}
\hline \multirow[b]{2}{*}{1} & \multirow[b]{2}{*}{$n$} & \multicolumn{2}{|l|}{ At diagnosis } & \multirow[b]{2}{*}{$\begin{array}{l}\text { Duration of } \\
\text { medical treatment } \\
\text { (months) }\end{array}$} & \multicolumn{2}{|c|}{ At time of operation } \\
\hline & & $\begin{array}{l}\text { Mean IOP } \\
\text { (untreated, } \\
m m \mathrm{Hg} \text { ) }\end{array}$ & $C / D$ ratio & & $\begin{array}{l}\text { Mean IOP } \\
\text { (treated, } \\
m m \mathrm{Hg} \text { ) }\end{array}$ & $C / D$ ratio \\
\hline $\begin{array}{l}\text { Group A } \\
\text { Group B }\end{array}$ & $\begin{array}{l}39 \\
39\end{array}$ & $\begin{array}{l}31(9 \cdot 6) \\
29(9 \cdot 4)\end{array}$ & $\begin{array}{l}0.6(0.2) \\
0.6(0.2)\end{array}$ & $\begin{array}{l}39 \cdot 7(59) \\
27.9(32)\end{array}$ & $\begin{array}{l}25.9(6.9) \\
24.9(6.3)\end{array}$ & $\begin{array}{l}0.6(0.1) \\
0.7(0.1)\end{array}$ \\
\hline
\end{tabular}

Standard deviations in parentheses.

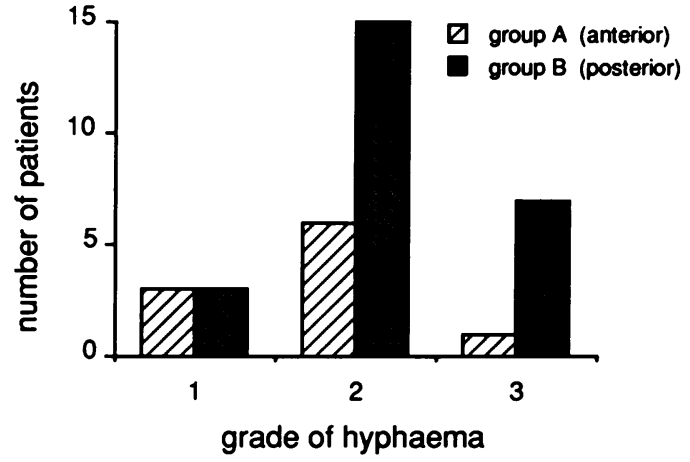

Figure 2 Frequency and severity of postoperative hyphaema. Grade 1, diffuse; grade 2, 0.2-1 mm; grade 3, greater than $1 \mathrm{~mm}$. Anterior dissection (group $A$ ) produced significantly fewer hyphaemas, and those which occurred were less severe. There were 39 eyes in each surgical group.

mation was recorded: depth of the anterior chamber; hyphaema (grade 1 - diffuse without formation of blood level; grade 2 - up to $1 \mathrm{~mm}$; grade 3 -more than $1 \mathrm{~mm}$ ), blood clot and other problems. The duration of hyphaema and stay in hospital were noted. Patient details were recorded 3 to 7 days after discharge and again about 6 to 8 weeks later. The final assessment was made approximately 4 months after the operation. The intraocular pressure was recorded after exclusion of possible steroid response at least 2 weeks after discontinuation of steroid eye drops ${ }^{23}$ and without supplementary medical treatment. The reason for beginning any supplementary medical treatment after the operation was also recorded. We analysed results for the whole study population and in addition examined separately the results for those patients with exfoliation glaucoma.

Differences between the groups were analysed by the two-sample $t$ test, the $\chi^{2}$ test, analysis of variance, and the Mann-Whitney $U$ test where appropriate. Values of $p$ of 0.05 or less were considered to be significant.

\section{Results}

All patients were Caucasians, and each group comprised 39 eyes of 39 patients. The patient characteristics for the two groups are shown in Table 1. There was no significant difference between the two groups (A and B) for sex, age, reason for diagnosis, and presence of systemic diseases (arterial hypertension, diabetes mellitus, haematological disorders). Table 2 shows the glaucoma status. At diagnosis there was no difference between the groups for intraocular pressure without medication, cup to disc ratio, prevalence of exfoliation, and duration of medical treatment. Similarly, there was no difference at the time of surgery for intraocular pressure with medication and cup to disc ratio. Neither was there any significant difference for severity of visual field loss at diagnosis and at time of surgery, or for indication for surgery (early trabeculectomy; failed medical treatment).

Twenty nine patients had their operation performed by three consultants, 12 by two senior registrars, and 37 by eight registrars. There was no bias for any level of seniority in the two groups.

In each group two patients were found to have 
Figure 3 Time of appearance of postoperative hyphaemas of different severity.

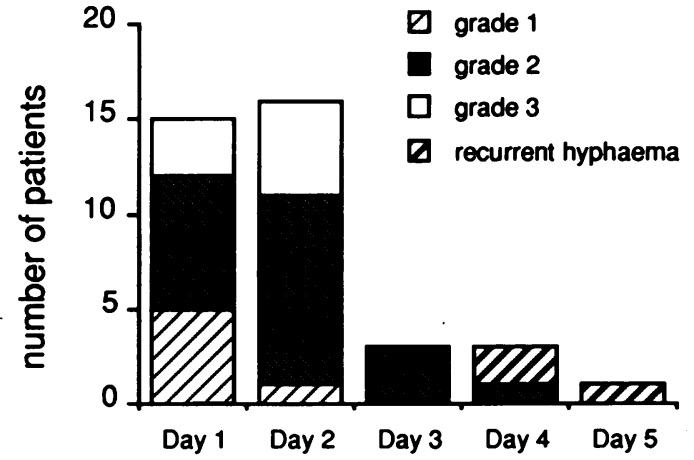

time of appearance of hyphaema

tissue specimens which did not correspond with the intended style of dissection, and these two patients were reclassified according to the histological findings. For the main analysis this histologically confirmed classification was used, but no significant difference in results was found between the histological classification and the classification based on the surgeon's intended dissection.

The frequency and severity of hyphaema in the two groups is shown in Figure 2. Thirty five patients (45\%) developed a hyphaema: six patients diffuse with no blood level, 21 with a level of $0.2 \mathrm{~mm}$ to $1 \mathrm{~mm}$, and eight with more than $1 \mathrm{~mm}$ blood level. There was no difference in the frequency of grade 1 hyphaemas (three patients in both groups). Group B had a significantly higher incidence of hyphaemas of both grade $2,0.2 \mathrm{~mm}$ to $1 \mathrm{~mm}$ height (15 patients versus six in group $A, p<0.05$ ) and grade 3 , more than $1 \mathrm{~mm}$ height (seven patients versus one in group $A, p<0.01$ ). If only hyphaema severe enough to form a detectable blood level is considered, there were seven out of 39 eyes (18\%) in group A, compared with 22 out of 39 eyes $(56 \%)$ in group B. The difference was statistically significant $(p<0.001)$.

The time of occurrence of hyphaema was analysed for the three grades of hyphaema (Fig 3). We disregarded the few circulating red blood cells which were present in the anterior chamber on the first day in nearly every case. Most hyphaemas of grade 1 (five out of six) were present on the first postoperative day, whereas only seven of 21 grade 2 and three of eight grade 3 hyphaemas were present on day one. Grade 1 was therefore significantly different from grades 2 and 3 in that respect. In the latter grades most hyphaemas appeared on the second (13/29) and third (5/29) postoperative day, with only one hyphaema (grade 2) appearing on day four.

Patients with hyphaema stayed significantly longer in hospital: mean, $4 \cdot 4$ days (SD 2.2), than those without: mean, 2.5 days (SD 0.5 ). Time in hospital was found to be related to the severity of hyphaema. Analysis showed that mean hospital stay for grade 1 hyphaema did not differ from grade 2 ( $3 \cdot 2$ days and $3 \cdot 6$ days respectively), but grade 3 patients stayed in hospital significantly longer, mean $7 \cdot 7$ days (SD 2 1 ). When compared with patients without hyphaema, those with both grade 2 and 3 stayed significantly longer in hospital, but grade 1 did not. Overall, group A patients remained in hospital for an average of
2.9 days (SF $1 \cdot 3$ ), compared with an average of 3.8 days (SD 1.9) for group $B$. The difference was significant (Mann-Whitney test, $\mathrm{p}=0.004$ ).

Patients with each of the three grades of hyphaema were compared with each other and with those without hyphaema to determine possible distinguishing features. Patients with hyphaema were similar to those without hyphaema with regard to age, sex, systemic diseases, intraocular pressure at diagnosis, cup to disc ratio at diagnosis, intraocular pressure at the time of surgery, and duration of medical treatment.

Out of the 15 patients with exfoliation glaucoma included in this study five (33\%) developed a hyphaema postoperatively. There was no case of a severe or recurrent hyphaema. There were seven patients in group $A$ and eight in group B who had exfoliation. In group A one of the seven patients had a diffuse hyphaema (grade 1) compared with one diffuse (grade 1) and three grade 2 hyphaemas in the eight exfoliation glaucoma patients in group $B$.

With reference to the individual analysis of the three grades of hyphaema, the only significant difference observed was in the sex distribution of grade 1 when compared with grade 2 ( $5: 1$ female to male ratio in grade 1 versus $6: 15$ for grade 2 ). However, there was no difference in the sex distribution between grades 1 and 3 and 2 and 3 . Three patients, all of them in grade 3 , experienced recurrent hyphaemas, two of them on the fifth postoperative day and one on the fourth day. These recurrent hyphaemas were of moderate degree, up to $2.5 \mathrm{~mm}$ in height, occurred prior to the complete resolution of a pre-existing hyphaema grade 3 , and they were not detrimental to the final visual acuity of these three patients.

The two groups, A and B - that is, anterior and posterior dissection and the patients with and without hyphaema - were compared with regard to immediate postoperative complications (anterior chamber depth, uveal effusion, and pain). No eyes required reoperation to correct surgical complications. There was no significant difference between the two randomised surgical groups and between the patients with and without hyphaema.

At approximately 4 months after the operation the final outcome was analysed with regard to reduction of visual acuity, final untreated intraocular pressure, rate of postoperative steroid response, and bleb morphology. One patient was lost to follow-up and one patient did not have sufficient follow-up. Both patients were in group A. No significant difference was noted between groups A and B or between those with hyphaema and those without. The untreated mean intraocular pressure was similar for group A, $15 \mathrm{~mm}$ (SD $4 \cdot 1$ ), and group B, $14.9 \mathrm{~mm}$ (SD 5.5). Similarly, the untreated intraocular pressure at 4 months of patients who had hyphaema, $15.7 \mathrm{~mm}$ (SD 5.3), was not significantly higher than that of the patients who did not experience a hyphaema, $14 \cdot 2 \mathrm{~mm}(\mathrm{SD} 4 \cdot 1)(\mathrm{p}=0 \cdot 18)$.

Examination of individual cases in which the intraocular pressure remained controlled after the operation only with the aid of medical therapy showed them to be distributed evenly between groups $A$ and $B$ and between those with 
and without hyphaema. Three patients in group A $(8 \%)$ and four patients in group B (10\%) required supplementary medical therapy (one medication each). Similarly, from the hyphaema group three patients $(8 \cdot 5 \%)$ required supplementary treatment compared with four patients $(10 \%)$ in the no-hyphaema group. One patient from group B with a grade 2 hyphaema suffering from thrombocytopenia was the only patient with uncontrolled intraocular pressure, despite medical therapy, after surgery.

\section{Discussion}

This prospective randomised study confirms the hypothesis that excision of the inner block anterior to the scleral spur is associated with a significant reduction in the incidence and severity of postoperative hyphaema. The two groups of patients were comparable, the only difference being the mode of dissection of the inner block. Group B, posterior dissection, was associated with the majority of the more severe hyphaemas (grade 3 ) and with all the recurrent hyphaemas.

The anterior dissection method (group A) should not be confused with 'Cairns-type' trabeculectomy.' Cairns excised trabecular meshwork up to the scleral spur and therefore was likely to have disturbed it in at least some cases. Our anterior dissection (guarded anterior fistula) is further forward and excises only cornea, all anterior to the angle structures.

The incidence of hyphaema in our study (45\%) is among the higher values quoted in the literature. ${ }^{3+16181922}$ This is not surprising, as our figure includes diffuse hyphaemas (six) and small hyphaemas that might have been overlooked in retrospective studies. Watkins and Brubaker found a similar incidence of hyphaema (43\%) in the partial thickness group of their study which compared prospectively partial-thickness and full-thickness filtration procedures.

Most diffuse hyphaemas, grade 1 , appeared in the first postoperative day. This suggests that in most cases they represent resolving peroperative bleeding. This is not the case with grades 2 and 3 , which appear later and are probably new events.

The anterior dissection, which removes only corneal tissue (guarded anterior fistula), is associated with a significantly lower incidence of postoperative bleeding. This suggests that the vascular components of sclera and the ciliary body are the most likely sources of hyphaema. This coincides with our occasional postoperative observation of blood streaming from the fistula site into the aqueous. It is also conceivable that in the dissection of the posterior block and peripheral iridectomy may be closer to the iris root. This study cannot, however, identify with certainty the source of postoperative hyphaema.

It is interesting to note that, although exfoliation glaucoma cases are known to have a varied degree of iris vasculopathy, ${ }^{24-26}$ this did not result in a higher frequency of bleeding. The number of patients with exfoliation glaucoma is too small for valid statistical analysis, but the overall incidence of hyphaema and the protective effect of anterior dissection were similar to that for the patients with primary open angle glaucoma.
The intraocular pressure attained with both methods of inner block dissection was similar and within the range quoted in the literature. ${ }^{+1+16172022}$ Our study confirms that varying the size and site of the fistula does not affect the final intraocular pressure. ${ }^{27}{ }^{28}$ Reduction of the filtration area (anterior dissection) did not influence the final outcome. It has been suggested that hyphaema might affect drainage. ${ }^{21}$ We found no significant difference in the surgical outcome (untreated mean intraocular pressure at 4 months) between patients with hyphaema and those without.

It is unlikely that the shape of the outer scleral flap would influence the result. We have gradually increased the use of triangular flaps over the last 10 years without alteration in the rate of either intraocular pressure control or complications, including hyphaema and shallow anterior chamber.

The main advantage of a modified dissection of the inner block is the lower incidence of postoperative hyphaema. This complication sometimes causes alarm to the patient and the surgeon and can influence the duration of hospital stay of the patient. In our study hyphaemas (grades 2 and 3 ) were associated with a significantly longer hospital stay, and so following the anterior dissection method should reduce costs. The extra cost of longer hospital stay after a trabeculectomy has recently been quantified. ${ }^{29}$

We are grateful to Professor William R Lee for assistance with the histological confirmation, Drs David Keating and Weng Sehu for assistance with statistical analysis, Ms Susan Lang for the illustration, sister Pauline Dabydeen for the randomisation, and all surgeons that took part in the study. This study was supported by a grant from the Alexander von Humboldt Foundation.

1 Cairns JE. Trabeculectomy. Preliminary report of a new method. Am $\mathcal{F}$ Ophthalmol 1968; 66: 673-9.

2 Watson PG. Trabeculectomy: a modified ab externo technique. Ann Ophthalmol 1970; 2: 199-205.

3 Watson PG. When to operate an open angle glaucoma. Eye 1987; 1: $51-4$

4 Watson PG, Barnett F. Effectiveness of trabeculectomy in glaucoma. Am $\mathcal{F}$ Ophthalmol 1975 79: 831-45.

Wilson MR. Posterior lip sclerotomy vs trabeculectomy in West Indian blacks. Arch Ophthalmol 1989; 107: 1604-8.

6 Lewis RA, Phelps CD. Trabeculectomy v thermosclerostomy A five-year follow-up. Arch Ophthalmol 1984; 102: 533-6.

7 Watkins Jr PH, Brubaker RF. Comparison of partialthickness and full-thickness filtration procedures in openthickness and full-thickness filtration procedures in

8 Lamping KA, Bellows AR, Hutchinson BT, Afran SI. Long term evaluation of initial filtration surgery. Ophthalmology term evaluation of

9 Watson PG, Grierson I. Place of trabeculectomy in the treatment of glaucoma. Ophthalmology 1981;88: 175-96.

10 Herschler J. What makes filtering procedures filter? Ophthalmic Surg 1984; 15: 471-2.

11 Murray SB, Jay JL. Trabeculectomy: its role in the management of glaucoma. Trans Ophthalmol Soc UK 1979; 99: 492-4.

12 Smith RJH. Medical versus surgical therapy in glaucoma simplex. Br F Ophthalmol 1972: 56: 277-83.

13 Jay JL, Allan D. The benefit of early trabeculectomy versus conventional management in primary open-angle glaucoma relative to severity of disease. Eye 1989; 3: 528-35.

14 Jay JL, Murray SB. Early trabeculectomy versus conventional management in primary open angle glaucoma. Brf Ophthalmol 1988; 72: 881-9.

15 Lavin MJ, Wormald RPL, Migdal CS, Hitchings RA. The influence of prior therapy on the success of trabeculectomy.

16 Mills KB. Trabeculectomy: a retrospective long-term followup of 444 cases. Br f Ophthalmol 1981; 65: 790-5.

17 Wilson P. Trabeculectomy: long-term follow-up. $\mathrm{Br} \mathfrak{F}$ Ophthalmol 1977; 61: 535-8.

18 Yamashita H, Eguchi S, Yamamoto T, Shirato S, Kitazawa Y Trabeculectomy: a prospective study of complications and results of long-term follow-up. $\mathcal{F}$ p $\mathcal{F}$ Ophthalmol 1985; 29: $250-62$.

19 Shuster JN, Krupin T, Kolker AE, Becker B. Limbus-vfornix-based conjunctival flap in trabeculectomy. Arch Ophthalmol 1984; 102: 361-2. 
20 Jerndal T, Lundstrom M. 330 trabeculectomies - a followup study through 1/2-3 years. Acta Ophthalmol (Kbh) 1977 55: 52-62.

21 Zaidi AA. Trabeculectomy: a review and 4-year follow-up. $B r$ f Ophthalmol 1980; 64: 436-9.

22 Ridgway AEA. Trabeculectomy. A follow-up study. $\mathrm{Br} \mathcal{F}$ Ophthalmol 1974; 58: 680-6.

23 Thomas R, Jay JL. Raised intraocular pressure with topical steroids after trabeculectomy. Graefes Arch Clin Exp Ophthalmol 1988; 226: 337-40.

24 Brooks AMW, Gillies WE. The development of microvascular changes in the iris in pseudoexfoliation of the lens capsule. Ophthalmology 1987; 94: 1090-7.

25 Konstas AGP, Marshall GE, Lee WR. Iris vasculopathy in exfoliation syndrome. An immunocytochemical study. Acto Ophthalmol (Kbh) 1991; 69: 472-83.
26 Ringvold A, Davanger $M$. Iris neovascularisation in eyes with pseudoexfoliation syndrome. Br 7 Ophthalmol 1981; 65: $138-41$.

27 Duzanec Z, Krieglstein GK. Correlation between regulation of intraocular pressure, anatomical localisation of trephination and trephine diameter in goniotrephination procedures: a prospective study. Klin Monatsbl Augenheilkd 1981; 178: 431-5.

28 Starita RJ, Fellman RL, Spaeth GL, Poryzees EM. Effect of varying size of scleral flap and corneal block on trabeculectomy. Ophthalmic Surg 1984; 15: $48+7$.

29 Ainsworth JR, Jay JL. Cost analysis of early trabeculectomy versus conventional management in primary open angle glaucoma. Eve 1991; 5: 322-8. 